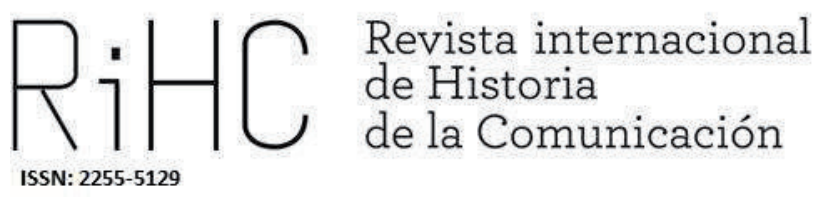

\title{
EL CINE DE ANIMACIÓN EN LA GUERRA CIVIL ESPAÑOLA: UNA APROXIMACIÓN A LA EXHIBICIÓN EN LAS SALAS DE MADRID DURANTE LA CONTIENDA
}

Animation films in the Spanish Civil War: An approach to the exhibition in the cinemas of Madrid during the war

DOI: http://dx.doi.org/10.12795/RiCH.2021.i16.17

Recibido: 24-2-2021

Aceptado: 3-5-2021

Publicado: 30-6-2021

Gonzalo Tirado

Universidad Carlos III de Madrid gonzalo_1984aC@hotmail.com ORCID (1) 0000-0002-1365-9248 
Resumen: Este artículo tiene como objetivo revelar la difusión que las producciones de animación, españolas y extranjeras, tuvieron en Madrid durante la Guerra Civil y conocer cuál fue la presencia y diversidad de las películas exhibidas en los cines de la capital. Para la investigación han sido utilizadas técnicas de la metodología cuantitativa aplicada a fuentes primarias de carácter hemerográfico. Asimismo, se ha hecho uso de técnicas de la metodología cualitativa, como la observación de materiales de época y la síntesis documental. Los resultados muestran que el cine de animación formaría parte de la vida cotidiana de la población madrileña durante toda la guerra, resultando una actividad de ocio habitual y una práctica social frecuente en la retaguardia, algo sorprendente en una ciudad que constituía un objetivo militar para los ejércitos enfrentados.

Palabras clave: cine de animación, años treinta, Segunda República, Guerra Civil.

\begin{abstract}
The objective of this article is to reveal the diffusion of spanish and foreign animation productions during the Spanish Civil War in Madrid and to know the presence and diversity of the films projected in the cinemas of Madrid. The research has used quantitative methodology techniques applied to primary sources of a hemerographic nature. Likewise, qualitative methodology techniques have been used, such as the observation of period materials and the documentary synthesis. The results explain that animated films were part of the daily life of the Madrid population in the war. It was a habitual leisure activity and a frequent social practice in the rear, something surprising in a city which was a military objective for the opposing armies.
\end{abstract}

Keywords: animated cinema, thirties, Second Spanish Republic, Spanish Civil War.

\title{
Introducción y metodología
}

Este trabajo pretende llevar a cabo una investigación que revele la difusión que las producciones de cine de animación, tanto españolas como extranjeras, tuvieron en Madrid durante la Guerra Civil. Este estudio puede hacer relevantes aportaciones a este campo, ya que se ha profundizado poco en el mismo. El principal objetivo es analizar la difusión y popularidad de artefactos culturales, tanto de procedencia local, como derivados de flujos transnacionales, en un período de convulsión política y social, para llegar a conocer la presencia que el cine de animación tuvo en la vida de la población madrileña durante la Guerra Civil.

Los temas relacionados con el cine de animación en España antes de 1939 han atraído muy poca atención por parte de los investigadores. En cuanto a la animación producida en España, en todo el siglo XX apenas pueden encontrarse un par de publicaciones sobre esta temática. La primera sería El cine sonoro en la II República (Gubern, 1977), seguida por Historia del dibujo animado español (Candel, 1993). En el siglo XXI, parece que ha surgido un mayor interés, editándose obras como Cine de animación en España (Yébenes, 2002), Del Trazo al Pixel. Un recorrido por la animación española (VVAA, 2015) o Animando lo imposible, los orígenes de la animación stop- 
motion (1899-1945) (Encinas Salamanca, 2017). Por otro lado, hay una publicación extranjera, llamada Cartoons: 110 años de cine de animación (Bendazzi, 2003), que incluye un capítulo dedicado exclusivamente a la animación española, escrito por Emilio de la Rosa. En cuanto a la investigación sobre la difusión del cine de animación extranjero en España durante los años treinta, la información es prácticamente inexistente, a excepción del artículo "Los filmes de animación en los cines del Madrid de entreguerras (1917-1939)" (Tirado, 2021), publicado en Hispania Nova.

Las producciones que conforman el objeto de estudio son aquellas, tanto españolas como extranjeras, pertenecientes al género del cine de animación, tanto de dibujos animados, como las que utilizaron la técnica de stop-motion, exhibidas en cines de Madrid entre el 18 de julio de 1936 y el 28 de marzo de 1939.

Se han utilizado técnicas procedentes del método cuantitativo y cualitativo. La perspectiva cuantitativa permite concretar con números aspectos específicos relativos al número de películas y semanas de exhibición, que dan respuesta a nuestros objetivos y a las preguntas de investigación. La cualitativa, en cambio, ofrece la posibilidad de profundizar en información acerca de la industria.

Toda investigación sobre este tema proporcionará unos resultados imprecisos, debido a la inexactitud de la información disponible. Meseguer (2010: 242-246) indica que este tipo de estudios que van más allá del campo de la producción, se encuentra con dificultades a la hora de extraer resultados precisos y concluyentes, ya que en la España de los años treinta no existe un registro administrativo sistemático de los datos referentes a la exhibición: ni cifras, ni taquilla, ni de todo lo exhibido incluyendo complementos de programa. Meseguer también indica que debido a la situación de guerra, se incrementa la exhibición no regulada en espacios provisionales, de modo que a la hora de realizar estadísticas solo se cuenta con un porcentaje insuficiente derivado de los datos que ofrecen las carteleras de prensa para el cine comercial.

La primera fase metodológica es la recopilación de fuentes primarias, tales como prensa o cualquier otro tipo de documentación fechada entre el 18 de julio de 1936 y el 28 de marzo de 1939 relacionada de algún modo con el cine de animación. Para ello, fueron enviadas peticiones de información a los siguientes organismos oficiales: Filmoteca Nacional, Instituto de la Cinematografía y de las Artes Visuales (ICAA), Centro Documental de la Memoria Histórica (CDMH) y Archivo General de la Administración (AGA). De forma análoga fueron enviadas solicitudes de información a organizaciones relacionadas con partidos y sindicatos que en aquella época pudieron tener relación con la industria cinematográfica, como la Fundación Pablo Iglesias, Largo Caballero, Archivo Histórico del PCE y Fundación Anselmo Lorenzo. La respuesta ha sido la remisión a fuentes hemerográficas debido a la inexistencia de documentación sobre este tema en los citados archivos, por lo que se ha procedido a la búsqueda de fuentes primarias en hemerotecas. Las revistas relacionadas de un 
modo u otro con la industria cinematográfica han sido Cinegramas, Popular Film, Mi Revista, Celuloide Madrileño y Arte y Cinematografía. Por otro lado, se ha recurrido a la selección de una muestra representativa de periódicos de este período, como $A B C$, Ahora, La Voz o La Libertad. El resultado ha sido positivo, ya que se ha hallado una cantidad notable de información.

Una vez localizada la documentación se ha considerado conveniente la aplicación de técnicas de la metodología cuantitativa focalizadas en el cálculo y la cuantificación de los datos que constituyen el objeto de estudio, es decir, el número de filmes exhibidos, así como el lugar de origen. Estos cálculos pueden visualizarse a través de tablas incluidas en el texto. En cuanto a las técnicas de la metodología cualitativa, se ha optado por la observación de las fuentes hemerográficas, tomando nota de aspectos como la fecha, el título de la película, la productora y el lugar de exhibición.

Para vincular los filmes anunciados en las carteleras de Madrid con los títulos originales se ha utilizado una base de datos de cortos clásicos de dibujos estadounidenses ${ }^{1}$. Los criterios para establecer la identificación han sido la similitud del título, temática o personajes comunes, una vez identificada la serie o la productora. Esta asociación se ha establecido mediante conclusiones exactas, intentando evitar la conjetura o la aproximación.

Aunque en los primeros cuatro capítulos se realiza un análisis de una parte de la información de carácter general, será el capítulo cuarto donde se procede a exponer los resultados obtenidos de la investigación en varias tablas, procediendo a la interpretación de dicha información en el mismo apartado. El quinto capítulo expondrá los resultados sobre la influencia que el cine de animación tuvo en la vida cotidiana de la España republicana en general, y de Madrid en particular, mediante el estudio de la prensa, la iconografía y testimonios de personas.

\section{Contextualización de la exhibición cinematográfica}

El período que enmarca el objeto de estudio es el comprendido entre el 18 de julio de 1936, fecha en la que se produce la sublevación militar en la península que daría lugar a la Guerra Civil, hasta la llegada de las tropas franquistas a Madrid el 28 de marzo de 1939. Cuando se inicia la guerra, en la cultura española ya habían irrumpido productos propios de la sociedad de masas de los países anglosajones, como el cine. En el período

\footnotetext{
${ }^{1}$ The Big Cartoon Database. Consultado el 31 de marzo de 2021 en https://www.bcdb.com/cartoons
} 
de entreguerras aumentan el poder adquisitivo y el tiempo de ocio de la población, por lo que ya en la década de los años treinta se hallarían plenamente asentados los medios de comunicación de masas, con la consolidación del cine como un medio de ocio y diversión, todo ello decisivo en la concepción de una nueva significación del entretenimiento (Eiroa, 2015: 45-46). Madrid no sería un caso aparte. La llegada del sonoro supuso una revolución a nivel mundial rompiendo con más de treinta años de proyecciones mudas. Teniendo en cuenta que en 1936 los sueldos oscilaban entre 100 y 300 pesetas mensuales y el precio medio de la entrada al cine era de una peseta (Montoliú, 1998: 13), se puede asegurar que la asistencia a este espectáculo era bastante asequible para los ciudadanos.

En 1935, en España había un total de 2.767 salas de cine, quedando 2.000 de ellas en la zona republicana al estallar la guerra. En Madrid había 46 salas el 17 de julio de 1936, una cifra alejada de las 116 que había en Barcelona (Martínez, 2009: 117-139). Una vez aplastada la sublevación en la capital, la vida volvería a una cambiada normalidad, volviendo a acudir a los cines, contando con 25 salas el 22 de julio de $1936^{2}$, menos de la mitad de las que se contabilizaban días antes de comenzar la guerra. Esta relativa calma se iría rompiendo a medida que el ejército insurrecto se acercaba a Madrid. Desde comienzos de noviembre, el frente de guerra llegaría a los barrios periféricos, por lo que, hasta el 23 de noviembre, la vida de la ciudad estaría orientada a resistir el asedio, repercutiendo en la actividad de ocio y cultural, que prácticamente se congelaría, aunque siempre llegó a haber dos o tres salas de cine que proyectaron películas esos días. Una vez estabilizado el frente, las salas volverían a abrir gradualmente.

Desde mediados de 1937 y hasta el final de la guerra, la escasez y la inflación formaban parte de la vida diaria en la ciudad, produciéndose también restricciones de electricidad, afectando esto directamente a las salas, sobre todo desde finales de 1938. Sorprendentemente, la afluencia de público a las salas de cine no cesó en momento alguno, a excepción de los días de marzo de 1939 correspondientes al golpe de Casado. No obstante, a comienzos de ese mes se contaban hasta 35 salas de cine en funcionamiento ${ }^{3}$, por lo que el volumen de salas abiertas se encontraba en su mejor momento desde el inicio de la guerra.

Cuánto mayores eran las dificultades en la vida diaria de los madrileños, mayor era su necesidad de evasión a través de distracciones y espectáculos como el cine.

\footnotetext{
2 "Cartelera Madrileña", Ahora, 17-22 de julio de 1936.

3 “Cartelera Madrileña”, $A B C, 05$ de marzo de 1939, p. 4.
} 


\section{Tipos de exhibición de cine de animación en Madrid}

Desde mediados de los años diez los dibujos animados estadounidenses habían alcanzado gran popularidad por Europa, habiendo constancia de proyecciones en Madrid ya en 19164 . Durante los años veinte, producciones de dibujos como Felix The Cat u otras de Fleischer Studios, Walt Disney y otros estudios, iban llegando a las salas madrileñas, que compartían pantalla con cortos españoles. El estreno en 1928 del filme de Disney, Steamboat Willie, considerado el primer dibujo con sonido, cambiaría el paradigma. Decenas de estudios reconvertirían sus creaciones para competir con los nuevos cánones, por lo que el mundo se vería inundado de este tipo de filmes. Durante la Segunda República es habitual ver anunciadas en los cines de Madrid producciones de Walt Disney, Fleischer Studios, Warner Bros, Universal, Columbia y otras compañías, popularizándose personajes como Mickey Mouse, Popeye o Betty Boop. Esta eclosión de la animación también haría aterrizar en Madrid filmes de stopmotion franceses y soviéticos. Análogamente, cortos españoles de dibujos y stopmotion asomarían tímidamente en las pantallas (Tirado, 2021: 145-165).

En 1936 encontramos una gran oferta de películas en Madrid con una cartelera dominada por el cine estadounidense. Los cortos de dibujos norteamericanos se distribuían como complementos de los largometrajes de Hollywood que se estrenaban en los cines. Eran elementos de relleno que las grandes compañías suministraban como acompañamiento de sus largos de acción real, que se adquirían por lo general, mediante contratos de distribución con pequeños estudios de animación (Bendazzi, 2003: 83).

Los cortos que enviaban las distribuidoras estadounidenses llegaban a España con el nombre de "complementos" o con el genérico "dibujos animados", provocando así que prácticamente no existan datos de los títulos de estos filmes de dibujos a efectos de distribución. No hay datos sobre la distribución de cine de animación de otros países, aparte de Estados Unidos, ni siquiera de la propia animación española.

Debido a que casi todos los datos acerca de la exhibición de cine de animación de Madrid solo pueden extraerse de las secciones de la cartelera de los periódicos, esta puede contener inexactitudes. Muchas veces estos filmes no eran anunciados o lo eran bajo un nombre genérico. Cuando eran anunciados, al ser traducidos, los títulos podían ser interpretados a criterio del exhibidor o el distribuidor.

Desde la llegada del sonoro, los circuitos de exhibición se habían multiplicado, proyectándose películas en cineclubs o incluso llegando a la exhibición doméstica. En

\footnotetext{
4 “Espectáculos", $A B C, 05$ de marzo de 1916, p. 17.
} 
el caso de filmes españoles, no sería descartable que algunos hubiesen sido exhibidos en proyecciones privadas.

Además de esta forma estándar de exhibir cine de animación, encontramos en Madrid las conocidas como "jornadas infantiles", que consistían en proyectar a lo largo de una tarde películas cómicas, instructivas y otras de dibujos, que solían terminar con un sorteo de juguetes entre los asistentes ${ }^{5}$. Hay constancia de estas sesiones dedicadas para niños, al menos desde $1917^{6}$. Al menos durante los meses previos a la Guerra Civil estas sesiones de los jueves por la tarde eran muy populares, donde se proyectaban dibujos de Walt Disney o Fleischer Studios ${ }^{7}$, y como ya se indicó, terminaban con un sorteo de juguetes. En ocasiones, el público lo formaban alumnos de las escuelas municipales y los establecimientos benéficos ${ }^{8}$.

Además existían otras sesiones en las que se proyectaban varios cortos de un mismo personaje o productora. Al menos hasta noviembre de 1938 las sesiones conocidas como "Semana Walt Disney", organizadas por salas como Actualidades, continuaban celebrándose, con su ritual de sesiones maratonianas de cortos de la compañía y el tradicional reparto de obsequios ${ }^{9}$.

Las "Semanas de Betty Boop" continuarían celebrándose por lo menos hasta mediados de 1938 , aunque ya no se anunciaba la entrega de muñecas u otros obsequios ${ }^{10}$, $\operatorname{como}^{2}$ era habitual en 1936. También aparecen anunciadas en Actualidades algunas "Semanas de Popeye" o "Semanas Paramount" entre $1936^{11}$ y $1939^{12}$.

El Cine Actualidades también organizó una "Semana de Warner Bros" a comienzos de 1938 , en la que se proyectaron varios cortos de dibujos de dicha compañía, en blanco y negro y en color. Igualmente ocurriría con los dibujos de Ub Iwerks Studios en la "Semana Ufilms", en 1938, o con los dibujos de Columbia, también el mismo año. También hay constancia de una "Semana CEC.", en la que se proyectaba material distribuido por Centro Español Cinematográfico, como los dibujos de Van Beuren

\footnotetext{
5 “Publicidad de Hollywood Cinema", Celuloide Madrileño, 15 de febrero de 1936, p. 5.

6 “Espectáculos”, $A B C, 07$ de noviembre de 1917, p. 15.

7 Julio Romano, "El cine ha convertido en realidad los sueños de los niños, porque todos quieren ser como Spanky, el pequeñuelo que hace lo que le da la gana", Cinegramas, 01 de marzo de 1936, pp. 2223.

8 "Publicidad del Día del Cinema-Año IV", Popular Film, 11 de junio de 1936, p. 10.

9 “Cartelera Madrileña”, $A B C, 02$ de junio de 1934 - 18 de noviembre de 1938.

10 "Cartelera Madrileña”, ABC, 27 de agosto de 1935 - 15 de mayo de 1938.

11 “Cartelera Madrileña”, Ahora, 23 de junio de 1936, p. 28.

12 “Cartelera Madrileña”, ABC, 24 de enero de 1938-05 de enero de 1939
} 
Studios $^{13}$. El transcurso de la Guerra Civil no solo no acabaría con estas jornadas infantiles, sino que las potenciaría.

Además de estas formas de exhibición de cortos de animación, hay que mencionar el caso particular de El Nuevo Gulliver (Ptushko, 1935), proyectada como cualquier película de larga duración y no como complemento.

\section{Evolución de la presencia en salas}

En los meses previos al estallido de la guerra se cuentan unos 48-46 cines en la capital ${ }^{14}$, de ellas, hasta seis salas anunciaban cine de animación, cifra que probablemente sea inferior a la cantidad real.

Tras el golpe de julio de 1936 se observa una caída en el número de salas que anunciaban cine de animación, al igual que ocurría con la cifra general de salas de cine en la capital, que descendía hasta $25^{15}$. Esto se debe a las primeras semanas de desorganización general, pero un mes y medio después el sector de la exhibición volvería a funcionar con relativa normalidad. Este incremento se verá frenado los primeros días de noviembre de 1936, coincidiendo con el inicio del asedio de la capital. Hasta que cesó el ataque, el 23 de noviembre, apenas funcionaron dos o tres salas en la capital, y sus proyecciones se orientaban generalmente al cine soviético y de propaganda ${ }^{16}$, aunque hubo espacio para los dibujos, como las proyecciones del corto Juguetilandia, algunos días de noviembre de $1936^{17}$.

Tras la Batalla de Madrid, la ciudad iba recuperando la normalidad y comenzaban a funcionar las salas. Durante los primeros meses de 1937 llegan a aparecer un número total de cero salas que anunciaban cine de animación, al menos hasta enero de 1938. Esto no parece que se deba a que los cines dejasen de exhibir este género, sino que se debe a la reducción del número de páginas en los periódicos, debido a la falta de papel (Montoliú, 1998: 260). Bajo la excusa del ajuste de espacio en las páginas de los diarios, las carteleras ya solo anunciaban el largo principal que proyectaban, obviando los complementos entre los que se encontraban los cortos. Las escasas exhibiciones de animación anunciadas en ese período se deben a proyecciones del largo de marionetas El Nuevo Gulliver.

\footnotetext{
13 “Cartelera Madrileña”, $A B C, 17$ de enero de 1938-05 de enero de 1939.

14 “Cartelera Madrileña”, Ahora, 16 de febrero de 1936 - 17 de julio de 1936.

15 “Cartelera Madrileña”, Ahora, 22 de julio de 1936, pp. 25-26.

16 “Cartelera Madrileña”, ABC, 5 - 10 de noviembre de 1936.

17 “Cartelera Madrileña”, Ahora, 10-14 de noviembre de 1936.
} 
Al despegar 1938 se puede apreciar un repunte en cuanto a presencia del cine de animación, llegando a igualarse al período previo a la guerra, pero gradualmente vuelve la austeridad de medios y una nueva reducción de páginas en los diarios, por lo que el espacio de la cartelera vuelve a limitarse a los largos. Las pocas referencias que aparecen entre mediados de 1938 y el fin de la guerra son las de las "semanas" dedicadas a Walt Disney, Betty Boop o Popeye, o bien a proyecciones de El Nuevo Gulliver. No obstante, la exhibición de películas se realizaba con normalidad, incluso llegó a haber el mayor número de salas de cine en cartelera, con un total de 35 salas en marzo de $1939^{18}$.

Además de las dificultades para cuantificar las salas que proyectaron cine de animación, también hay que añadir las vicisitudes que debió sufrir la exhibición cinematográfica en Madrid tras el comienzo de la guerra. Un bombardeo, un altercado o un apagón eléctrico podían alterar la programación. También debe tenerse en cuenta que había otras formas de exhibición, tales como proyecciones organizadas por las organizaciones de izquierda, cineclubs, pases privados, aparatos de exhibición doméstica o incluso proyecciones no reguladas, fruto de la piratería de películas.

El cine Actualidades concentra el mayor número de proyecciones anunciadas, aunque realmente se pueden encontrar en más de una decena de salas. Este cine se convirtió en el gran templo de la animación en Madrid. Situado en la actual calle Gran Vía, 48, era de sesión continua, esto es, que realizaba varias proyecciones seguidas, sin interrupción, desde la mañana hasta la noche.

\section{Los filmes de animación proyectados en Madrid durante la Guerra Civil}

En la Guerra Civil se proyectaron un total de 140 filmes de animación diferentes (137 de dibujos animados y 3 de stop-motion), de los cuales, solo se conoce la productora y/o la procedencia de 104 de ellos. De los 36 restantes solamente se conoce el título que le pusieron en España y las semanas que estuvieron en cartelera, ya que no han podido ser identificados.

Dentro de los 104 filmes de los que se conoce al menos la productora y el país de procedencia, 102 son cortos de dibujos estadounidenses. Las excepciones son el corto de stop-motion español titulado Españoladas (Gijón, 1934) y el largo soviético de acción real con stop-motion El Nuevo Gulliver. Este último fue el único largometraje de

18 “Cartelera Madrileña”, $A B C, 05$ de marzo de 1939, p. 4. 
los 104 filmes. No se encuentra filme alguno de otros países que no sean Estados Unidos, la URSS o España.

En los meses previos a la guerra más de la mitad de los filmes proyectados fueron producidos el año anterior, por lo que la cartelera de aquellos meses estaba bastante modernizada. En cambio, durante la guerra, se observa un estancamiento en la llegada de nuevas producciones, recurriendo a filmes muy anteriores, pero lo más importante es que no hay exhibición de filmes realizados entre 1937 y 1939, llegando incluso a ser muy escasa la cantidad correspondiente a 1936, por lo que la mayoría de los filmes proyectados durante la guerra fueron producidos entre 1932 y 1935 . Esto se debe a que a lo largo de 1937 cada vez era más habitual que los nuevos filmes traídos de Estados Unidos, a pesar de llegar a las dependencias de las filiales en España, quedasen almacenados y no llegasen a estrenarse. Esto se debió a la falta de pago de los derechos de importación de las películas extranjeras estrenadas, impago provocado por la inexistencia de divisas (Sala Noguer, 1993: 303). Es decir, aunque Hollywood obtenía dinero por el alquiler de nuevos estrenos en zona republicana, no podía cobrarlo, ya que se quedaba inmovilizado en las cuentas españolas de las compañías (Cabeza San Deogracias, 2005: 102), debido a un decreto del Gobierno de la República que impedía la exportación de capital. Esta situación se hizo insostenible para las multinacionales, por lo que en otoño de 1937 cesó la afluencia regular de películas extranjeras a la zona republicana (Sala Noguer, 1993: 303) hasta el final de la guerra.

\subsection{Estados Unidos}

Las productoras estadounidenses presentes en los cines de Madrid durante la Guerra Civil fueron Walt Disney, Fleischer Studios, Ub Iwerks Studios, Columbia, Warner Bros, Van Beuren Studios y Metro Goldwyn Meyer. A diferencia de lo que ocurría semanas antes del inicio de la guerra, no consta en cartelera que se proyectasen filmes de Terrytoons o Universal, pero es probable que se continuasen exhibiendo sus cortos animados.

\subsubsection{Walt Disney: Mickey Mouse y Silly Symphonies}

Walt Disney, cuyos filmes fueron distribuidos en España por Artistas Asociados ${ }^{19}$, filial de United Artists, es la productora de la que constan más títulos estrenados, hasta un total de 41 cortos, mayoritariamente en color. De ellos, hay constancia de 27 filmes cómicos de Mickey Mouse, así como de catorce capítulos de la serie Silly Symphonies. El largometraje Blancanieves y los Siete Enanitos, estrenado en Estados Unidos en diciembre de 1937, no llegó a hacerlo en España hasta 1941, debido a las reticencias

19 "Publicidad de Artistas Asociados", Arte y Cinematografía, 1 de mayo de 1936, p. 332. 
de las multinacionales a enviar películas de nuevo estreno a la República, tras las restricciones económicas impuestas por el gobierno.

En los cortos protagonizados por Mickey exhibidos en Madrid, dicho personaje aparecía acompañado en ocasiones, de Pluto, Goofy, Minnie Mouse, Pato Donald, La Vaca Clarabella o el Caballo Horacio. Se pueden encontrar piezas tan conocidas como The Band Concert o Building a building, candidato este último al Oscar al Mejor Cortometraje Animado en 1933.

Tabla 1. Mickey Mouse: cortometrajes proyectados en Madrid durante la Guerra Civil

\begin{tabular}{|c|c|c|}
\hline Cortometraje & Título original, año & $\begin{array}{l}\text { Semanas en } \\
\text { cartelera }\end{array}$ \\
\hline Concierto de banda & The Band Concert, 1935 & 3 \\
\hline Mickey, constructor & Building a building, 1933 & 3 \\
\hline Secuestro canino & The Dognapper, 1934 & 3 \\
\hline La apisonadora de Mickey & Mickey's Steamroller, 1934 & 2 \\
\hline Mickey y el gigante & Giantland, 1933 & 2 \\
\hline Partida de campo & Orphan's Picnic, 1936 & 2 \\
\hline Mickey trovador & Ye olden days, 1933 & 1 \\
\hline El doctor Z & The Mad Doctor, 1933 & 1 \\
\hline Mickey, bombero & Mickey's Fire Brigade, 1935 & 1 \\
\hline ¡Vaya un perro! & Playful Pluto, 1934 & 1 \\
\hline Canguro de Mickey & Mickey's Kangaroo, 1935 & 1 \\
\hline Mickey, adoptivo & Mickey plays papa, 1934 & 1 \\
\hline Las Navidades de Mickey & Mickey's good deed, 1933 & 1 \\
\hline Micky en el campo & Camping out, 1934 & 1 \\
\hline A través del espejo & Thru the mirror, 1936 & 1 \\
\hline La opera de Mickey & Mickey's Grand Opera, 1936 & 1 \\
\hline Mickey, caballista & Two gun Mickey, 1934 & 1 \\
\hline La gran carrera de Mickey & The Steeple Chase, 1933 & 1 \\
\hline Mickey, aprendiz & The pet store, 1933 & 1 \\
\hline Partida de polo & Mickey's Polo Team, 1936 & 1 \\
\hline La pesadilla de Mickey & Mickey's Nightmare, 1932 & 1 \\
\hline Trade Mickey & Trader Mickey, 1932 & 1 \\
\hline Mickey, futbolista & Touchdown Mickey, 1932 & 1 \\
\hline
\end{tabular}




$\begin{array}{llr}\text { El canario de Mickey } & \text { The Wayward Canary, } 1932 & 1 \\ \text { Gran Gala de Mickey } & \text { Mickey's Gala Premiere, 1933 } & 1 \\ \text { Camarada Mickey } & \text { Mickey's pal Pluto, 1933 } & 1 \\ \text { Deportes de invierno } & \text { On Ice, } 1935 & 1\end{array}$

Fuente: Elaboración propia, a partir de la información obtenida de la cartelera de cines de Madrid de los diarios Ahora, ABC, La Libertad y La Voz

Se exhibieron en Madrid catorce piezas de la serie Silly Symphonies, filmes musicales de gran influencia para el resto de productoras, que no dudaron en imitar el estilo de esta serie, creando otras similares.

Tabla 2. Silly Symphonies: cortometrajes proyectados en Madrid durante la Guerra Civil

\begin{tabular}{lll} 
Cortometraje & Título original, año & $\begin{array}{l}\text { Semanas en } \\
\text { cartelera }\end{array}$ \\
\hline Tres lobitos & Three Little Wolves, 1936 & 4 \\
El gallito del lugar & Cock o'the walk, 1935 & 3 \\
Los bebés acuáticos & Water babies, 1935 & 2 \\
El Rey Midas & The Golden Touch, 1935 & 2 \\
Leyenda de Pascua & Funny Little Bunnies, 1934 & 2 \\
El lobo feroz & The Big Bad Wolf, 1934 & 2 \\
Juguetes olvidados & Broken toys, 1935 & 2 \\
Los pingüinos & Peculiar Penguins, 1934 & 1 \\
¿Quién mató al Petirrojo? & Who killed cock Robin, 1935 & 1 \\
El gato bandido & The Robber Kitten, 1935 & 1 \\
La diosa Primavera & The Goddess of Spring, 1934 & 1 \\
Gente Menuda & Bugs in love, 1932 & 1 \\
El carnaval de los pasteles & The cookie carnival, 1935 & 1 \\
Rey Neptuno & King Neptune, 1932 & 1 \\
\hline
\end{tabular}

Fuente: Elaboración propia, a partir de la información obtenida de la cartelera de cines de Madrid de los diarios Ahora, ABC, La Libertad y La Voz

\subsubsection{Fleischer Studios: Popeye, the Sailor, Betty Boop y Color Classics}

De Fleischer Studios se pueden encontrar en cartelera un total de 41 cortos, convirtiéndose en la segunda productora con más títulos exhibidos en el período de estudio. De estos cortos, que distribuía Paramount, dieciocho pertenecerían a la serie Popeye, the Sailor, once a Betty Boop y tres a la serie Color Classics. Hay filmes de los 
que ha resultado imposible identificar el título original, teniendo solo constancia de la serie.

En los filmes exhibidos de la serie Popeye, the Sailor, conocida en España como Popeye, el Marinero, aparecen personajes secundarios tan célebres como Olivia, Bluto o Pilón. Todos los capítulos fueron en blanco y negro.

Tabla 3. Popeye, the Sailor: cortometrajes proyectados en Madrid durante la Guerra Civil

\begin{tabular}{|c|c|c|}
\hline Cortometraje & Título original, año & $\begin{array}{l}\text { Semanas en } \\
\text { cartelera }\end{array}$ \\
\hline Donde las dan, las toman & No identificado & 4 \\
\hline Pasen a comer, señores & We aim to please, 1934 & 3 \\
\hline El hombre del trapecio & The Man on the Flying Trapeze, 1934 & 3 \\
\hline Más vale ser torero & For better or Worser, 1934 & 2 \\
\hline Soy lo que soy/Así soy yo & I Yam what I Yam, 1933 & 2 \\
\hline Un duelo morrocotudo & Choose your weapins, 1935 & 2 \\
\hline Palo de Ciego & Can you take it, 1934 & 1 \\
\hline El rival de Vulcano & Shoein'Hosses, 1934 & 1 \\
\hline El terror del cuadrilátero & Let's you and Him Fight, 1934 & 1 \\
\hline Me las pagaréis, villanos & No identificado & 1 \\
\hline Pregúntame otra & Axe me another, 1934 & 1 \\
\hline Hipnotizador, hipnotizado & The "Hyp-Nut-Tist", 1933 & 1 \\
\hline Profesor de gimnasia & Vim, Vigor y Vitaliky, 1936 & 1 \\
\hline Torero de ocasión & l eat my spinach, 1933 & 1 \\
\hline Si no te callas, te doy & Sock-a-by, baby, 1934 & 1 \\
\hline Dos valientes submarinos & Dizzy Divers, 1935 & 1 \\
\hline A puñetazo limpio & No identificado & 1 \\
\hline
\end{tabular}

De la serie Betty Boop se proyectaron once cortometrajes, todos en blanco y negro.

Tabla 4. Betty Boop: cortometrajes proyectados en Madrid durante la Guerra Civil. 


$\begin{array}{lll}\text { Betty, caza la mosca } & \text { Swat, the fly, 1935 } & 3 \\ \text { El barbudo de la montaña } & \text { The old man of the mountain, 1933 } & 3 \\ \text { Betty, transformista } & \text { No identificado } & 2 \\ \text { Betty sigue la moda } & \text { Keep in Style, 1934 } & 2 \\ \text { No y mil veces no } & \text { No! No! A thousand Times No!!, 1935 } & 2 \\ \text { Agua, jabón y cepillo } & \text { A little soap and water, 1935 } & 2 \\ \text { iVaya calor! } & \text { Red Hot Mamma, 1934 } & 1 \\ \text { Betty se vuelve sirena } & \text { Betty Boop's Life Guard, 1934 } & 1 \\ \text { Basta de ruidos } & \text { Stop that noise, 1935 } & 1 \\ \text { El abuelito de Betty } & \text { Betty Boop and Grampy, 1935 } & 1 \\ \text { Se vende todo } & \text { Betty Boop's Ups and Downs, 1932 } \\ \text { Fuente: Elaboración propia, a partir de la información obtenida de la cartelera de cines de Madrid de los } & 1\end{array}$

A imitación de Silly Symphonies, Fleischer Studios también realizó una serie de cortos musicales en color, llamada Color Classics, de la que constan tres piezas exhibidas en Madrid.

Tabla 5. Color Classics: cortometrajes proyectados en Madrid durante la Guerra Civil.

\begin{tabular}{lll} 
Cortometraje & Título original, año & $\begin{array}{l}\text { Semanas en } \\
\text { cartelera }\end{array}$ \\
\hline Bailando en la Luna & Dancing on the moon, 1935 & 2 \\
El cantar de los pájaros & The song of the birds, 1935 & 1 \\
Los niños en el zapato & The kids in the shoe, 1935 & 1
\end{tabular}

Fuente: Elaboración propia, a partir de la información obtenida de la cartelera de cines de Madrid de los diarios Ahora, ABC, La Libertad y La Voz

\subsubsection{Ub Iwerks Studios: Whillie Whopper y ComiColors}

Ub Iwerks Studios es la tercera compañía estadounidense con más cortos en cartelera, siendo un total de nueve piezas distribuidas por UFilms ${ }^{20}$, de las que uno de ellos pertenece a la serie protagonizada Whillie Whopper y otros ocho a la serie ComiColors (imitación de Silly Symphonies).

Tabla 6. Ub Iwerks Studios: cortometrajes proyectados en Madrid durante la Guerra Civil.

20 “Cartelera Madrileña”, $A B C, 15$ de febrero de 1938, p. 6. 


\begin{tabular}{|c|c|c|}
\hline Cortometraje & Título original, año (serie) & $\begin{array}{l}\text { Semanas } \\
\text { en } \\
\text { cartelera }\end{array}$ \\
\hline El jinete sin cabeza & The Headless Horseman, 1934 (ComiColors) & 3 \\
\hline Ali Babá & Ali Baba, 1936 (ComiColors) & 2 \\
\hline Jack y el Gigante & Jack and the Beanstalk, 1933 (ComiColors) & 2 \\
\hline iViva Willie! & Viva Willie, 1934 (Whillie Whopper) & 1 \\
\hline Sastrecillo Valiente & The Valiant Tailor, 1934 (ComiColors) & 1 \\
\hline $\begin{array}{l}\text { Aladino } \\
\text { La madre vieja y su perro }\end{array}$ & $\begin{array}{l}\text { Aladdin and the Wonderful Lamp, } 1934 \\
\text { (ComiColors) }\end{array}$ & $\begin{array}{l}1 \\
1\end{array}$ \\
\hline La gallina roja & Old mother hubbard, 1933 (ComiColors) & 1 \\
\hline Reina de corazones & $\begin{array}{l}\text { The Little Red Hen, } 1934 \text { (ComiColors) } \\
\text { The Queen of Hearts, } 1934 \text { (ComiColors) }\end{array}$ & 1 \\
\hline uente: Elaboración propia, & $\begin{array}{l}\text { artir de la información obtenida de la cartelera de ci } \\
\text { diarios Ahora, ABC, La Libertad y } L a \text { Voz }\end{array}$ & Arid de los \\
\hline \multicolumn{3}{|c|}{ 4.1.4 Columbia: Scrappy y Color Rhapsody } \\
\hline \multicolumn{3}{|c|}{$\begin{array}{l}\text { Hay constancia de al menos siete filmes de Columbia. Dos pertenecían a la serie } \\
\text { Scrappy y otro dos a la serie de dibujos musicales Color Rhapsody, emulación de Silly }\end{array}$} \\
\hline \multicolumn{3}{|c|}{$\begin{array}{l}\text { Symphonies. Semanas antes del estallido de la guerra fueron proyectados en Madrid } \\
\text { cortos de la serie Krazy Kat, por lo que no sería descartable que durante el conflicto } \\
\text { bélico continuasen proyectándose. Hay tres cortometrajes de esta compañía que no } \\
\text { han podido ser identificados. Buigas \& Soler SL sería la encargada de distribuir las } \\
\text { producciones de Columbia en España }{ }^{21} \text {. }\end{array}$} \\
\hline
\end{tabular}

Tabla 7. Columbia: cortometrajes proyectados en Madrid durante la Guerra Civil.

$\begin{array}{lll}\text { Cortometraje } & \text { Título original, año (serie) } & \begin{array}{l}\text { Semanas en } \\ \text { cartelera }\end{array} \\ \text { El pequeño explorador } & \text { No identificado (Scrappy) } & 2 \\ \text { Don Cholo está chalao } & \text { No identificado } & 2 \\ \text { Traje dominguero } & \text { Sunday clothes, 1931(Scrappy) } & 1 \\ \text { Enanos zapateros } & \text { The shoemaker and the Elves, 1935 (Color } & 1 \\ & \text { Rhapsody) } & 1 \\ \text { Un mono sentimental } & \text { Monkey love, 1935 (Color Rhapsody) }\end{array}$

21 "Publicidad de Buigas y Soler SL", Arte y Cinematografía, 1 de mayo de 1936, p. 398. 


\begin{tabular}{|c|c|c|}
\hline Galopín, galopando & No identificado & 1 \\
\hline El disector & No identificado & 1 \\
\hline
\end{tabular}

\subsubsection{Warner Bros: Looney Tunes y Merrie Melodies}

A pesar de la difusión que tuvieron los dibujos de Warner Bros en Estados Unidos, en España tuvieron una presencia minoritaria, contando con seis títulos proyectados en Madrid, siendo la filial española de la propia compañía la encargada de su distribución. Uno de los títulos sería una pieza de Looney Tunes, cortos cómicos que tanto éxito obtendrían años después. Otros cuatro filmes pertenecerían a la serie musical Merrie Melodies, imitación de Silly Symphonies. También hay constancia de un cortometraje del que no ha sido posible identificar la serie a la que pertenecía. En los cortos exhibidos durante la guerra no hay constancia de personajes como Porky, Pato Lucas o Bugs Bunny, que ya estaban adquiriendo fama internacional.

Tabla 8. Warner Bros: cortometrajes proyectados en Madrid durante la Guerra Civil.

\begin{tabular}{|c|c|c|}
\hline Cortometraje & Título original, año (serie) & $\begin{array}{l}\text { Semanas en } \\
\text { cartelera }\end{array}$ \\
\hline iViva Buby! & Viva Buddy, 1934 (Looney Tunes) & 1 \\
\hline Mi Fedora & My green Fedora, 1935 (Merrie Melodies) & 1 \\
\hline Joven y con salud & Young and healthy, 1933 (Merrie Melodies) & 1 \\
\hline $\begin{array}{l}\text { Eres muy } \\
\text { descuidado }\end{array}$ & $\begin{array}{l}\text { You're too careless with your kisses, } 1932 \\
\text { (Merrie Melodies) }\end{array}$ & 1 \\
\hline $\begin{array}{l}\text { El Señor y la Señora } \\
\text { En ausencia del } \\
\text { tendero }\end{array}$ & $\begin{array}{l}\text { Mr. and Mrs. Is the same, } 1935 \text { (Merrie } \\
\text { Melodies) } \\
\text { No identificado }\end{array}$ & $\begin{array}{l}1 \\
1\end{array}$ \\
\hline
\end{tabular}

\subsubsection{Van Beuren Studios: Tom \& Jerry y Rainbow Parade}

Estos estudios trajeron a España varias de sus producciones, encargándose Centro Español Cinematográfico (CEC) de su distribución ${ }^{22}$. En el caso de Madrid aparecen hasta cinco cortos. Dos de ellos pertenecerían a la serie Tom \& Jerry, que no debe confundirse con la serie homónima de Metro Goldwyn Meyer creada en 1939. Van Beuren Studios también dedicaría una serie de cortos musicales, como emulación de Silly Symphonies, llamada Rainbow Parade, y de la que constarían tres piezas proyectadas. Estos estudios recuperaron al célebre personaje El Gato Félix.

22 “Cartelera Madrileña”, $A B C, 17$ de mayo de 1938, p. 8. 
Tabla 9. Van Beuren Studios: cortometrajes proyectados en Madrid durante la Guerra Civil.

\begin{tabular}{|c|c|c|}
\hline Cortometraje & Título original, año (serie) & $\begin{array}{l}\text { Semanas en } \\
\text { cartelera }\end{array}$ \\
\hline El cohete fantasma & The phantom rocket, 1932 (Tom \& Jerry) & 1 \\
\hline $\begin{array}{l}\text { Tom y Guerry en viaje a La } \\
\text { Luna }\end{array}$ & The Rocketers, 1932 (Tom \& Jerry) & 1 \\
\hline Linternas japonesas & $\begin{array}{l}\text { Japanese lanterns, 1935(Rainbow } \\
\text { Parade) }\end{array}$ & 1 \\
\hline Pánico en el pic-nic & Picnic Pacnic, 1935 (Rainbow Parade) & 1 \\
\hline $\begin{array}{l}\text { El Gato Félix y la Corte del } \\
\text { Rey Neptuno }\end{array}$ & $\begin{array}{l}\text { Neptune Nonsense, } 1936 \text { (Rainbow } \\
\text { Parade) }\end{array}$ & 1 \\
\hline
\end{tabular}

\subsubsection{Metro Goldwyn Meyer: Happy Harmonies}

Los dibujos de esta compañía tuvieron una discreta presencia, encargándose la propia compañía de la distribución en España. Hay constancia de dos cortos proyectados, correspondientes a la serie musical Happy Harmonies, enésima imitación de Silly Symphonies, entre los que cabe hacer mención a The discontented canary (1934), que muestra a unos primitivos Silvestre y Piolín.

Tabla 10. Happy Harmonies: cortometrajes proyectados en Madrid durante la Guerra Civil.

$\begin{array}{lll}\text { Cortometraje } & \text { Título original, año } & \begin{array}{l}\text { Semanas en } \\ \text { cartelera }\end{array} \\ \text { El canario descontento } & \text { The discontented canary, 1934 } & 1 \\ \text { Tres monitos formales } & \text { Good Little Monkeys, 1935 } & 1\end{array}$

\subsection{URSS: Mosfilm y el largometraje EI Nuevo Gulliver}

El Nuevo Gulliver, llamado originalmente Novvy Gulliver, es el único largo de animación identificado del que hay constancia en la cartelera madrileña. Esta película de la productora soviética Mosfilm, que combina personajes reales con stop-motion, tuvo una presencia constante desde $1935^{23}$. Su condición de largometraje facilitó que sus

23 “Cartelera Madrileña”, $A B C, 24$ de diciembre de 1935, p. 47. 
proyecciones se anunciaran en prensa, apareciendo en cartelera al menos siete semanas durante la guerra.

\subsection{España: El anecdótico caso de Españoladas}

En todo el período analizado solo ha sido encontrada una proyección de animación española, que sería el corto Españoladas, anunciado como de "marionetas", creado por Salvador Gijón en 1934 y proyectado durante una semana a comienzos de $1938^{24}$. Filmoteca Nacional indica que no conservan copias del mismo (Encinas, 2017: 138).

Durante la guerra, Salvador Gijón rodaría dos cortos de stop-motion, La bruja de la cueva (1939) y en colaboración con Antonio del Amo, Alerta (1938) (Yébenes, 2002: 15), pero no hay constancia de la exhibición de los mismos. También durante la contienda José Martínez Romano y "Menda" realizaron un filme de dibujos titulado Don Juan y Doña Inés (1939) (Candel, 1993: 11), pero tampoco consta su proyección en cines.

\section{El cine de animación en la vida cotidiana}

\subsection{Prensa}

Las producciones de Walt Disney o de Fleischer Studios conseguían hacerse un hueco en la prensa, aunque restringiendo su presencia a publicaciones especializadas, ya que la atención que la prensa generalista dedicaba al cine de animación era nula.

Durante la contienda, dichas revistas prestarían atención a la repercusión que Walt Disney tenía en otros países, como las celebraciones en Francia y España del 8o aniversario de la creación de Mickey Mouse ${ }^{25}$. También Cinegramas se hizo eco del homenaje que hicieron en Irlanda al famoso personaje ${ }^{26}$. Las publicaciones especializadas mostrarían especial atención a estrenos o proyectos futuros de Disney. A finales de 1937, Mi Revista hablaría del estreno mundial de Blancanieves y los Siete

\footnotetext{
24 “Cartelera Madrileña", $A B C, 22$ de febrero de 1938, p. 6.

25 “A través del mundo del film. Walt Disney y Mickey", Popular Film, 24 de diciembre de 1936, p. 7.

26 "Una orquesta Mickey Mouse", Cinegramas, 19 de julio de 1936, p. 31.
} 
Enanitos $^{27}$, publicando semanas después una reseña acerca del estreno en Estados Unidos $^{28}$, incluso anunciando que existía una versión doblada al castellano ${ }^{29}$. En cuanto a futuros proyectos, Mi Revista publicó un artículo sobre el estreno mundial de Pinocho, que Disney tenía previsto para $1938^{30}$, algo que no ocurrió hasta 1940. Esta revista llegó a difundir un par de fotos dedicadas y autografiadas por el dibujante y productor de Disney, T. Santiago Oppenheimer ${ }^{31}$.

Aunque en los meses previos a la guerra Fleischer Studios tuvo presencia en la prensa cinematográfica, durante la contienda apenas aparece un artículo, en el que Popeye fue utilizado como elemento propagandístico del bando republicano ${ }^{32}$. En cuanto a producciones animadas de otros países, se pueden encontrar reportajes en la primavera de 1936, desapareciendo en el período bélico.

\subsection{Cómic}

Desde 1925 podemos encontrar cómics en España basados en los dibujos animados de Felix the Cat, aunque fue a mediados de los años treinta cuándo se produce el gran boom del cómic español basado en el dibujo animado. En 1934 y 1935 saldrían a la luz cómics protagonizados por Mickey Mouse, Donald, Pluto, Popeye (Martín, 1978: 89139) o Betty Boop ${ }^{33}$. Ninguna de estas publicaciones sobrevivió al verano de 1936. Sin embargo, la necesidad de evasión y de ocio en la retaguardia, motivó que en zona republicana reapareciesen en el cómic estos personajes, como fue el caso de las historietas de Betty Boop, dibujadas por Petigris ${ }^{34}$. Debido al despliegue propagandístico provocado por el conflicto, en 1937 apareció la revista Pionero, que incluyó historietas de Popeye, en las que luchaba junto a los republicanos contra el fascismo ${ }^{35}$. También apareció la historieta La Vuelta al Mundo de Colas y Barullo para Mundo Gráfico, que publicó un capítulo en 1937 en el que se mostraba, a través de

27 "Mickey Mouse y Minnie y Donaldo son actores que han pasado a formar parte del elenco Radio Films", Mi Revista, 01 de noviembre de 1937, p. 25.

${ }^{28}$ C. Cámara "Hollywood visto por dentro. La ciudad R. K. O Radio", Mi Revista, 20 de enero de 1938, p. 31.

${ }^{29}$ T. Santiago Oppenheimer “Mickey Mouse, Minnie, Donaldo, Pluto y compañía”, Mi Revista, 15 de abril de 1938, pp. 25-26.

30 "Pantalla barcelonesa. Crítica y comentarios", Mi Revista, 15 de julio de 1938, p. 116.

${ }^{31}$ T. Santiago Oppenheimer, op. cit.

32 “Popeye, el marinero", Mi Revista, 01 de abril de 1937, pp. 15-17.

33 Andrés Álvarez, Tebeosfera. Consultado el 12 de abril de 2021 en https://www.tebeosfera.com/numeros/cine-aventuras 1935 marco 1.html

34 Petigris, "Betty Boob", Mi Revista, 20 de enero de 1938, p. 42.

35 José Manuel Rodríguez Humanes y Manuel Barrero, Tebeosfera. Consultado el 12 de abril de 2021 en https://www.tebeosfera.com/colecciones/pionero el 1937 ofpe.html 
Mickey Mouse, una crítica al bombardeo franquista sobre el madrileño barrio de Argüelles.

\subsection{Cine de acción real y teatro}

La relación del cine de animación con el cine de acción real o el teatro es anecdótica. En el mediometraje creado por la productora anarquista SIE-Films, iNosotros somos así! (Rodríguez González, 1937), se puede observar que en una de las escenas, Betty Boop, Popeye y Mickey Mouse forman parte del decorado. También cabe mencionar los números teatrales para niños que se representaban en el Teatro Zarzuela de Madrid en 1938, en los que unos humoristas anunciaban números cómicos sobre Mickey Mouse y Betty Boop ${ }^{36}$, que pudieron tratarse de una representación con los actores disfrazados o de un número de ventriloquia.

\subsection{Merchandising}

En el Madrid de 1936 a 1939 el merchandising relacionado con dibujos animados estaba muy extendido. Las casas de juguetes producían una gran cantidad de artículos con la imagen de Popeye, vendiéndose con gran facilidad, ocurriendo lo mismo con los libros relacionados, que se agotaban a los pocos días ${ }^{37}$. También hay testimonios que cuentan que en todas partes se vendían insignias, pañuelos y figuritas de este personaje, incluso algunas agitando la bandera anarquista, ya que parece ser que los militantes de esta ideología tenían predilección por él (Hochschild, 2018: 79).

Además de la venta en comercios, los grandes centros de reparto de merchandising eran los cines que organizaban las semanas monográficas. Como ya se ha indicado, en estas jornadas, además de visionar cortos, se efectuaban repartos de juguetes. Es cierto que aunque se siguieron celebrando durante toda la guerra, el reparto de merchandising, como caretas, cuentos, álbumes de pinturas infantiles o muñecos, se circunscribe prácticamente a los meses previos a la sublevación. Además, conocemos la existencia de otros artículos relacionados, como los almanaques. La Editorial Alas publicitaba un almanaque infantil con dibujos de Mickey, Los Tres Cerditos, Bimbo o Betty Boop, indicando que habían vendido más de 100.000 ejemplares $^{38}$. También la Editorial Molino puso a la venta almanaques de Mickey Mouse ${ }^{39}$. Igualmente, consta

\footnotetext{
36 "Cartelera madrileña”, $A B C, 11-21$ de agosto de 1938

37 “Popeye, el marinero", Mi Revista, 01 de abril de 1937, pp. 15-17.

38 "Anuncio de Editorial Alas", Arte y Cinematografía, 01 de mayo de 1936, pp. 212-408.

39 José Manuel Rodríguez Humanes y Manuel Barrero, Tebeosfera. Consultado el 12 de abril de 2021 en https://www.tebeosfera.com/numeros/mickey 1935 molino extra 1.html 2008
} 
que se fabricasen puzzles de Mickey, como los que puso a la venta Almacenes Arias, una vez socializados durante la guerra.

\subsection{Iconografía y testimonios}

Resulta imprescindible conocer el impacto de la iconografía en la vida cotidiana y los testimonios de los niños que vivieron la guerra. Aunque toda esta información no sea concretamente de Madrid, sirve para contextualizar la relación que había entre grandes ciudades de la retaguardia y el cine de animación. Un ejemplo fue el desfile de la "Semana Infantil" organizado por el Gobierno de la República, el 10 de enero de 1937 en Valencia, donde desfilaron carrozas dedicadas a Betty Boop, Mickey, Minnie o Los Tres Cerditos, que compartían evento con otras de Stalin o Largo Caballero ${ }^{40}$. También hay constancia de bares que decoraban el local con motivos de dibujos animados $^{41}$.

El cine de animación también se paseaba por las líneas del frente. La imagen de Popeye o Betty Boop fue utilizada frecuentemente por militantes anarquistas, mientras que Mickey era apreciado por militantes de todas las ideologías de la zona republicana, incluso por soldados del ejército sublevado (Hochschild, 2018: 79). Por otro lado, parece ser que en el frente de Aragón llegaron a entrar en combate tanques que portaban en la parte frontal un dibujo de Popeye ${ }^{42}$. En el frente de Madrid hay un interesante testimonio del estadounidense James M. Hepbron, donde relata que la figura de Mickey podía encontrarse en casi todas las oficinas gubernamentales y en las celdas de prisioneros, así como en el departamento infantil de la cárcel de mujeres de Madrid, decorado con varias figuras de Disney. También explica que, tras algunos combates en Madrid, un enorme anuncio eléctrico de Mickey Mouse situado en plena línea de fuego, quedó intacto tras el fuego cruzado. Igualmente, Hepbron hace referencia a la omnipresencia de Mickey en los cines de la capital ${ }^{43}$. Asimismo, en la denominada Batalla de Madrid era frecuente que los aviones soviéticos decorasen el fuselaje con dibujos de Mickey, Betty Boop o Popeye, algo que también hacían los aviadores alemanes de la Legión Condor.

Como el cine de animación estaba orientado al público infantil, no es extraño encontrar referencias iconográficas con el punto de vista de niños que vivieron aquellos años, desde dibujos de Mickey pintados en refugios antiaéreos (Moreno y

\footnotetext{
40 J. Fernández Caireles, "Crónica en Valencia. Una magnífica cabalgata ha cerrado los festejos de la Semana Infantil”, Crónica, 17 de enero de 1937, p. 8.

41 "Popeye, el marinero", Mi Revista, 01 de abril de 1937, p. 16.

42 “Popeye, el marinero", Mi Revista, 01 de abril de 1937, p. 15.

43 “Mickey Mouse ha cumplido ocho años", Popular Film, 15 de octubre de 1936, pp. 12-14.
} 
Sapena, 2017: 123-141) hasta un dibujo realizado durante la guerra por el niño Julián Díaz, dónde se representó a Mickey Mouse tocando un instrumento, posiblemente tras haberlo visto en el circo, en un corto o en un cuento (Gallardo Cruz y Gallardo Camacho, 2011: 78-105).

Además de estas evidencias gráficas, pueden encontrarse otros testimonios. En abril de 1937, en el barco dónde varios niños fueron evacuados desde Bilbao hasta Bélgica, los soldados republicanos trataron de animarles proyectando películas de Popeye (Payá Rico, 2018: 209-224). Ya en el Madrid republicano, podemos encontrar testimonios como el de Luis Otero Fernández, nacido en 1932, que recuerda que en 1938 o 1939 acudía a unos comedores de ayuda a niños en El Viso, donde les daban tebeos del ratón Mickey (Reverte y Thomás, 2001: 204). También cabe destacar el testimonio del director de cine de animación Cruz Delgado, nacido en 1929, que recuerda cuando poco antes de la guerra, acudió al cine San Carlos, situado en la calle Atocha, para ver el corto Los tres cerditos, traducción de Three Little Pigs (1933), que según él, le marcaría para siempre (San Román y Delgado, 2015: 16).

\section{Conclusiones}

Aunque en la sección de prensa donde se anunciaba la programación de los cines de Madrid muchas veces se omitían los cortos de dibujos proyectados, hay constancia de que este tipo de cine se proyectaba con normalidad en varias salas, principalmente en el cine Actualidades. Hay indicios para pensar que, aunque esto no se plasmase en la cartelera, los filmes de animación se proyectarían con la misma habitualidad con que lo hacían los largometrajes.

En resumen, entre el 18 de julio de 1936 y el 28 de marzo de 1939, aparecen 140 filmes de animación anunciados en las carteleras de prensa. La gran mayoría son cortos de dibujos producidos en Estados Unidos. El largo soviético El Nuevo Gulliver y el corto español Españoladas, ambos de stop-motion, serían las excepciones.

Dentro de la producción estadounidense se pueden encontrar cortos de Walt Disney, Fleischer Studios, Warner Bros, Ub Iwerks Studios, Columbia, Van Beuren Studios y Metro Goldwyn Meyer, no siendo descartable que también se proyectasen filmes de Terrytoons y Universal. Durante la guerra, la serie de dibujos animados que proyectó más títulos diferentes fue Mickey Mouse, seguida de Popeye, the Sailor. Por detrás de estas, encontramos Silly Symphonies, Betty Boop y ComiColors. El largometraje Blancanieves y los Siete Enanitos no llegó a estrenarse en España hasta 1941, debido, parece ser, a las reticencias de las multinacionales desde 1937 para enviar nuevas películas de estreno a la España republicana. 
Además de Estados Unidos, las fuentes indican que no hubo proyecciones de filmes de animación de otros países, a falta de las dos excepciones citadas.

El filme de animación más presente en las salas según la cartelera fue el largo soviético El Nuevo Gulliver, seguido de cortos de dibujos de Popeye, the Sailor, así como de las Silly Symphonies y los cortos de Mickey Mouse, ambos de Disney.

La prensa especializada en cine o espectáculos dedicó artículos a Walt Disney o Fleischer Studios. Igualmente, estos dibujos tuvieron presencia en cómics y otros productos de merchandising. Análogamente se puede encontrar la iconografía de estas producciones en la vida cotidiana, incluso para decorar edificios oficiales y armamento de guerra. También son recordadas en testimonios de niños de la época.

Como conclusión final, aunque probablemente, solo se conozca la punta del iceberg de las producciones de animación exhibidas, los dibujos estadounidenses tuvieron una gran difusión en las salas de cine de Madrid, al igual que el citado largo soviético. Sus protagonistas llegaron a ser tan célebres entre la población madrileña como cualquier actor o actriz de Hollywood. También habría que destacar la relación entre dibujos animados y contexto de guerra, basada en un elemento aparentemente infantil y humorístico, utilizado por un público habitante de un entorno donde la violencia y la relación directa con la muerte estaban presentes en la vida cotidiana.

\section{Fuentes y bibliografía}

\section{Referencias bibliográficas}

BENDAZZI, G. (2003). Cartoons: 110 años de cine de animación. Madrid: Ocho y Medio.

CABEZA SAN DEOGRACIAS, J. (2005). El descanso del guerrero. El cine en Madrid durante la Guerra Civil Española (1936-1939). Madrid: Lumen.

CANDEL, J. M. (1993). Historia del dibujo animado español. Murcia: Tres Fronteras.

DE LA ROSA, E. (2003). “Cine de animación en España”. En BENDAZZI, G., Cartoons: 110 años de cine de animación. Madrid: Ocho y Medio. pp. 469-508.

EIROA, M. (2015). "Entre el backstage y el frontpage". En Diego MAYORAL, Carlos PÉREZ (coords.), Mujeres de cine: ecos de Hollywood en España, 1914-1936. Madrid: Ministerio de Asuntos Exteriores y de Cooperación. Secretaría de Estado de Cooperación Internacional y para Iberoamérica: AECID, pp. 36-54. 
ENCINAS SALAMANCA, A. (2017). Animando lo imposible, los orígenes de la animación stop-motion (1899-1945). Madrid: Diábolo.

GALLARDO CRUZ, J. A. y GALLARDO CAMACHO, E. M. (2011). “La música dibujada por niños durante la Guerra Civil Española”, en Música y educación, no 85, pp. 78105.

GUBERN, R. (1977). El cine sonoro en la Il República (1929-1936). Barcelona: Lumen.

HOCHSCHILD, A. (2018). España en el corazón: Historia de los brigadistas americanos en la Guerra Civil Española. Madrid: Malpaso Ediciones.

MARTIN, A. (1978). Historia del cómic español: 1875-1939. Barcelona: Gustavo Gili.

MARTINEZ, J. (2009). "Del rojo al azul. Las pantallas de las dos Españas", en Espacio, tiempo y forma, Serie V, Historia Contemporánea, no 21, pp. 117-139.

MONTOLIÚ, P. (1998). Madrid en la Guerra Civil. La Historia. Vol. I. Madrid: Sílex Ediciones.

MORENO, A. y SAPENA, T. (2017). "Refugios antiaéreos: patrimonio de la Guerra Civil en la ciudad de Valencia", en Debats. Revista de cultura, poder y sociedad, no 131 (2), pp. 123-141.

NICOLÁS MESSEGUER, M. (2010). “El mercado cinematográfico español durante la Guerra Civil”, en Archivos de la Filmoteca, no 64-65, pp. 242-246.

PAYÁ RICO, A. (2018). "Infancia y exilio: Historias de vida de los niños de la Guerra Civil Española en Bélgica", en História da Educaçao, vol. 22, no 55, pp. 209-224.

REVERTE, J. M. y THOMÁS, SOCORRO (2001). Hijos de la guerra. Testimonios y recuerdos. Madrid: Temas de Hoy.

SALA NOGUER, R. (1993). El cine en la España Republicana durante la Guerra Civil. Bilbao: Mensajero.

SAN ROMÁN, J. y DELGADO SÁNCHEZ, C. (2015). De Don Quijote a Los Trotamúsicos. Madrid: Diábolo Ediciones.

TIRADO, G. (2021). “Los filmes de animación en los cines del Madrid de entreguerras (1917-1939)", en Hispania Nova, no 19, pp. 141-165.

VVAA (2015). Del trazo al pixel. Un recorrido por la animación española. Barcelona: Cameo.

YEBENES, P. (2002). Cine de animación en España. Barcelona: Ariel. 


\section{Referencias hemerográficas}

$A B C$ (Madrid), ejemplares consultados desde el 05 de marzo de 1916 hasta el 28 de marzo de 1939.

Ahora, ejemplares consultados desde el 16 de febrero de 1936 hasta el 05 de diciembre de 1938.

Arte y Cinematografía, 01 de mayo de 1936.

Celuloide Madrileño, 15 de febrero de 1936.

Cinegramas, ejemplares consultados desde el 01 de marzo de 1936 hasta el 19 de julio de 1936.

Crónica, 17 de enero de 1937.

La Libertad, ejemplares consultados desde el 05 de marzo de 1938 hasta el 11 de febrero de 1939.

La Voz, 27 de marzo de 1939.

Mi Revista, ejemplares consultados desde el 01 de abril de 1937 hasta el 15 de julio de 1938.

Popular Film, ejemplares consultados desde el 11 de junio de 1936 hasta el 24 de diciembre de 1936.

\section{Otras fuentes}

The Big Cartoon Database. Disponible en https://www.bcdb.com/cartoons/

Tebeosfera. Disponible en https://www.tebeosfera.com 